\title{
SELECTION, ESTABLISHMENT AND MAINTENANCE OF WOODY ORNAMENTAL PLANTS FOR HIGHWAY PLANTINGS
}

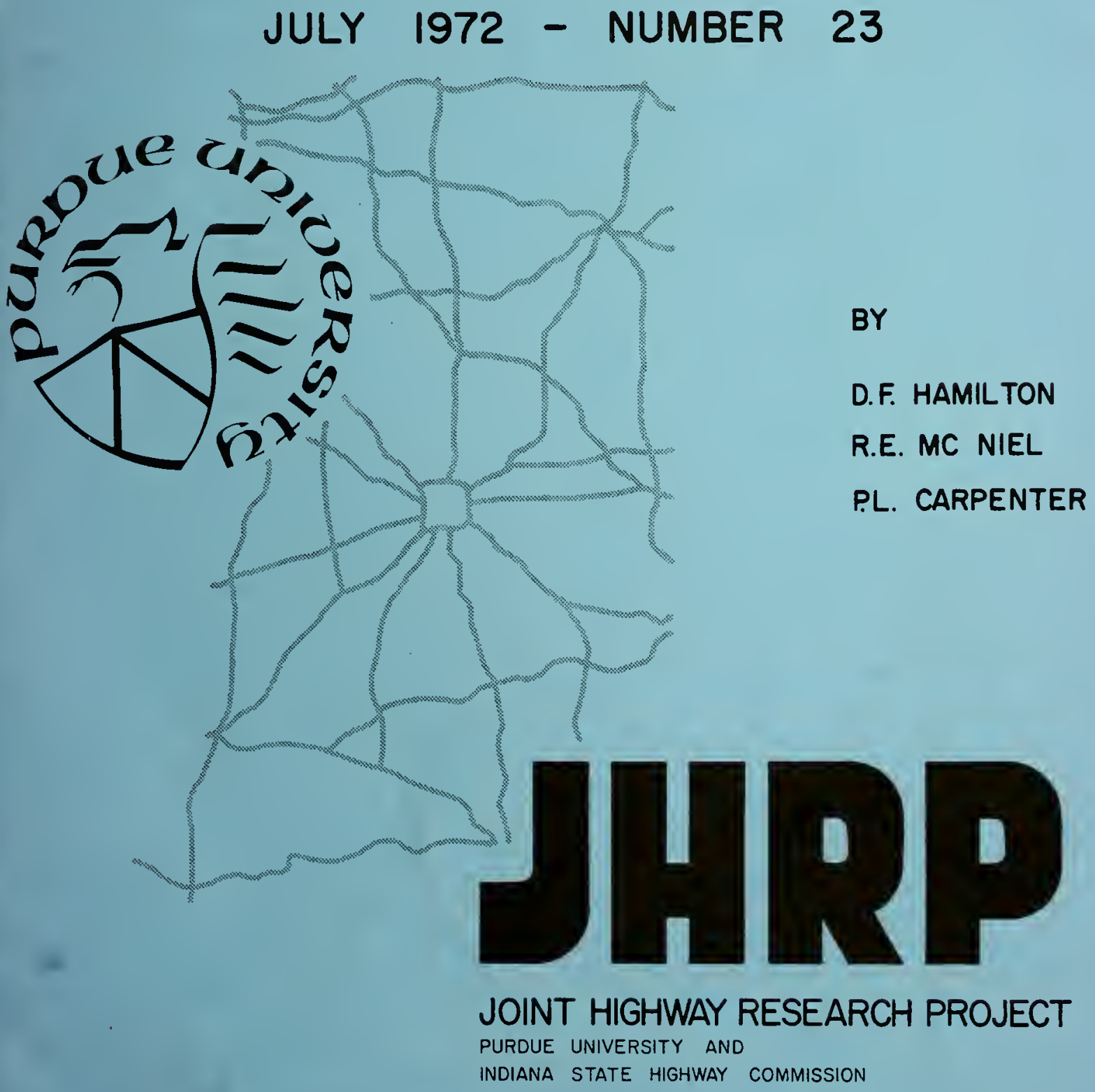





\section{Final Report}

SELECTION, ESTABLISHMENT AND MAINTENANCE OF WOODY ORNAMENTAL PLANTS FOR HIGHWAY PLANTINGS

T0: J.F. Mclaughlin, Director Joint Highway Research Project

FROM: H. L. Michael, Associate Director Joint Highway Research Project
July, 26, 1972

Project: C-36-48C

File: $\quad 9-5-3$

The attached is the Final Report on Part II, "Selection; Establishment and Maintenance of Woody Ornamental Plants for Highway Plantings" of the HPR Part II Research Study titled "Research in Roadside Development and Maintenance". This Report has been prepared by Messrs. D. F. Hamilton, R. E. McNiel and P. L. Carpenter, the present investigators on this portion of the Study.

The Report is a summary of the several investigations made under this Part of this Study and the results obtained. A section on conclusions and practical applications of the results is also included.

The Final Report is presented for acceptance as fulfillment of the objectives of this Part II of the Study. It will be forwarded for review, comment and similar acceptance to ISHC and FHWA.

IILM : ms

Respectfully submitted,

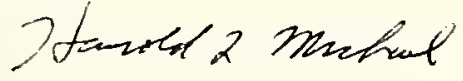

Harold L. Michael Associate Director cc: W. L. Dolch

R. L. Eskew

W. H. Goetz

W. L. Grecco

M. J. Gutzwiller

G. K. Hallock
R. H. Harre11

M. L. Hayes

C. W. Love11

G. W. Marks

R. D. Miles

J.W. Miller
C. F. Scholer

M. B. Scott

J. A. Spooner

N. W. Steinkamp

H. R. J. Walsh

E. J. Yoder 
Digitized by the Internet Archive in 2011 with funding from

LYRASIS members and Sloan Foundation; Indiana Department of Transportation 
SELECTION, ESTABLISHMENT AND MAINTENANCE OF WOODY

ORNAMENTAL PLANTS FOR HIGHWAY PLANTINGS

by

D. F. Hamilton, Graduate Assistant in Research

R. E. McNiel, Graduate Assistant in Research

P. L. Carpenter, Research Associate

Department of Horticulture

School of Agriculture, Purdue University

Joint Highway Research Project

Project No.: C $-36-48 \mathrm{C}$

File No.: $9-5-3$

Prepared as Part of an Investigation

Conducted by

Joint Highway Research Project

Engineering Experiment Station

Purdue University

In cooperation with the

Indiana State llighway Commission

and the

U.S. Department of Transportation

Federal Highway Administration

The contents of this report reflect the views of the author who is responsible for the facts and the accuracy of the data presented herein. The contents do not necessarily reflect the official views or policies of the Federal Highway Administration. This report does not constitute a standard, specification, or regulation. 
Table of Contents

Page

Introduction . . . . . . . . . . . . . . . . . . . 1

Weed Control in Roadside Plantings. . . . . . . . . . . . 2

Effects of Herbicide Combinations for Broad Spectrum Weed Contro1

in Ornamental Plantings . . . . . . . . . . . . . . 4

Herbicide Studies in Landscape Plantings. . . . . . . . . . 6

Establishing Roadside Slopes by Direct Seeding with Legumes, and

Woody Ornamentals and by Seedlings of Ornamental Plants . . . 7

Root Cuttings for Roadside Slope Stabilization . . . . . . . 9

Nitrogen Availability to Woody Plant Species as Influenced by

Nitrogen Fixation ................... . . 11

Response to Nitrogen from Three Slow Release Fertilizers . . . . 13

Factors Influencing Dehardening and Rehardening of Forsythia $x$

intermedia Stems. . . . . . . . . . . . . . . 15

Conclusions and Practical App1ications . . . . . . . . . . 19 


\section{Introduction}

The research carried out on this project consisted of two major areas of investigation. The prime purpose of both areas of research was to reduce maintenance requirements and, hence, maintenance costs of roadside plantings. The first area studies involved developing a herbicide program for landscape plantings. Three interim reports were filed which provide details of the techniques used, results obtained, and the conclusions drawn from the research. This final report presents summaries of the work plus suggested herbicide programs for weed control in landscape plantings.

The second phase involved investigations on methods of establishing plant material rapidly on slopes to reduce erosion and hence, lower maintenance costs. Also, involved were nutritional studies to determine the best procedure for suppling nitrogen to plants in the roadside landscape. The roadside soils many times are stripped of top soils and the subsoils are nutrient deficient. Nitrogen is the key element and if supplied to landscape plants establishment should be quicker and growth more vigorous. Maintenance and replacement costs should be reduced. Four interim reports were filed and the final report presents summaries of the results.

An interim report was filed on work in another area, plant cold hardiness. The information was thought to be of interest to highway personne1. This research indicated that winter storage temperatures of plants to be used on highway landscape sites is critical. 
Weed Control in Roadside Plantings

Purpose

The primary objectives of this phase of the research program were:

(1) to investigate methods of chemical weed control specifically designed for roadside plantings;

(2) devise new techniques to facilitate the application of these chemical herbicides and

(3) provide protective measures for woody ornamental plants that may be injured by the herbicides. These three objectives were considered separately under the following headings:

(a) Herbicide Combinations

(b) Incorporation of Herbicides in Mulches

(c) The Use of Activated Carbon for Socalized Herbicide Protection

\section{Results and Applications}

From greenhouse and field plot studies the combination of simazine at 1 1b/A and diphenamid at 4 1bs/A was shown to give extended control over a broad spectrum of weeds. Because of the lower concentrations of the individual herbicide components, the possibility of reducing injury to sensitive crop plants is suggested.

The incorporation of dichlobenil into various mulches provided equal or more effective weed control than if either the dichlobenil 
or mulch was used alone. Certain mulches, such as composted sawdust and crushed corncobs provided better weed control the second year than peat moss. Increasing the depth of mulch up to 4 inches increased the weed control and with the mulch used, which contained sawdust composted with $\mathrm{N}, \mathrm{P}$, and $\mathrm{K}$, the increased depth also increased the growth of many of the plants in the study as much as 300-400 percent.

The use of activated carbon for localized protection of plants sensitive to certain herbicides such as simazine appears to be promising, Iimited to the extent of protection it can provide. Time of application and method are important in determining effectiveness. 


\section{Effects of Herbicide Combinations for Broad Spectrum Weed Control in Ornamental Plantings}

\section{Abstract}

The objectives of this study were to explore the possibilities of combining herbicides to control a broad spectrum of weeds, to control activity for specific periods of time, and to reduce crop toxicity.

Initially, minimum concentrations necessary to control specific weeds was determined for various herbicides. Combinations of various levels of these herbicides were made to obtain broad spectrum weed control. From greenhouse and field plot studies the combination of simazine $(1 \mathrm{lb} / \mathrm{A})+$ diphenamid $(4 \mathrm{lb} / \mathrm{A})$ was shown to give the most effective control over a broad spectrum of weeds.

In the second year, additional herbicides were field tested, alone and in combination, to determine their effectiveness for ornamental plantings. These herbicides were applied as surface or soil incorporated treatments during various times of the year. Simazine-diphenamid applied to the surface gave excellent weed control if applied in April or June but was not persistent when applied in November. The dichlobemil (2 1b/A) + diphenamid ( $4 \mathrm{lb} / \mathrm{A})$, another good combination, was shown to be more effective if incorporated; in fact, dichlobenil effectiveness in all treatments was dependent on incorporation. 
Trifluralin ( $2 \mathrm{lb} / \mathrm{A}$ ), incorporated at twice the recommended rate, gave excellent broad spectrum weed control at all times tested.

Injury to various ornamental species was apparent when simazine was applied at its normal recommended rates. When simazine was used at its minimum effective concentration in combination with diphenamid, no injury occurred to the sensitive species, Euonymus fortunei 'Coloratus'. Another sensitive species, Ajuga 'Metallica-crispa,' was slightly injured early in the summer, but the injury was not apparent by late summer. Thus, the reduction in crop toxicity to some species was demonstrated by use of minimum effective concentrations of herbicides in combination.

Trifluralin and bensulide were found to be safe for all species tested. In pre-tested soils, these herbicides were non-toxic to selected species, even at four times the normal rate. Dichlobenil was found to be toxic to all species in the pre-treated soil.

The final phase of the investigations was to determine the amount of residual activity of the various herbicide treatments. A bioassay was conducted which, although highly variable, showed that bensulide and trifluralin exhibited significant residual activity over 11 months. 
Herbicide Studies in Landscape Plantings

Abstract

Test plots were set up in the Fort Wayne area to study various herbicide-mulch combinations and to study various pre-emergence and contact herblcide combinations.

Results and Applications

The problems unique with controlling weeds in highway landscape plantings have been partially solved. The following recommendations can be made for consideration by highway management personnel.

1. A bark mulch with dichlobenil 4 1b/A incorporated w 111 provide satisfactory control of weeds in landscape plantings.

2. Use this mulch-herbicide combination only on those plants 1isted on the dichlobenil label.

3. Further work needs to be done on other methods of applying herbicides to landscape plantings. Sand and the cellulose blanket used as carriers are not satisfactory.

4. Paraquat can be used to reduce or "knock down" established weed growth in shade trees and areas where the green portions of the crop plant will not be in contact with the herbicide.

5. Combinations of herbicides using Paraquat and pre-emergence materials will provide one season weed control.

6. Paraquat is hazardous to use and safety precautions should be followed. 


\author{
Establishing Roadside Slopes by Direct Seeding \\ with Legumes, and Woody Ornamentals \\ and by Seedlings of Ornamental Plants
}

\begin{abstract}
Field experiments to determine the feasibility of stabilizing roadside slopes by direct seeding with legumes and woody ornamentals and by seedlings of ornamentals were conducted from May 1968 through September 1971. Plantings were made in spring and fall and survival observed periodically. No fertilization or watering programs were maintained for the experiments.
\end{abstract}

\title{
Results
}

Initial survival and establishment of seedlings did not appear to be influenced by spacing at planting. However, growth rates were better at wider spacings.

Seedlings of nitrogen-fixing species survived better along highway slopes than seedlings of non-nitrogen fixers. Spring plantings gave better survival than fall plantings.

Direct seedling of woody ornamentals gave only marginal results. However, direct seeding of some nitrogen-fixing species appears promising along highways. 
Direct seeding of legumes on roadside slopes did not give complete cover unless mulched when seeded.

\section{Applications}

Spring planting of seedlings at spacings thrce feet or wider are recommended for roadside plantings of Ligustrum amurense, Cercis canadensis, Elaeangnus angustifolia, Polygonum reynoutria,

Hemerocallis sp., and Yucca glauca.

Travois and Teton alfalfa at $20 \mathrm{lbs} / a c r e$, and Dawn birdsfoot trefoil at $10 \mathrm{lbs} /$ acre should provide good cover on roadsides when planted in spring and mulched.

Direct seeding of Robinia pseudoacacia and Cercis canadensis will give adequate roadside cover. 
Root Cuttings for Roadside Slope Stabilization

Abstract

Root cuttings were planted along roadside slopes to determine the feasibility of stabilizing roadside slopes with woody plant materials propagated from root cuttings. No fertilization or watering programs were maintained for the roadside tests.

Time of planting of root cuttings was found critical. Spring plantings were much more successful than fall plantings. In the spring root cuttings of Rhus glabra produced the most rapid cover of the plants evaluated.

Greenhouse experiments were conducted to determine the possibility of promotion of rooting in root cuttings with chemicals. Response was marginal and further work is needed to determine their success on the highway planting site.

\section{Conclusions and Applications}

1. Root cuttings of Rhus glabra planted at two per square foot is sufficient to give complete and rapid tree cover on roadside slopes. Overwintering of root cuttings of Rhus established the first year is good.

2. Root cuttings of Robinia hispida planted at one per square foot is enough to produce adequate tree cover, but is slower growing than Rhus glabra. Overwintering of root cuttings of Robinia established 
the first year is excellent.

3. Establishment of Comptonia peregrina by root cuttings four per square foot along highway roadside is not sufficient for adequate stabilization and cover.

4. Fal1 planting of root cuttings is not recommended. None of the root cuttings studied survived the winter and produced growth the following spring.

5. Treatment of root cuttings of Comptonia peregrina with growth promoting substances increases the number of roots formed.

These experiments have shown that root cuttings are definitely a feasible way to establishhighway slopes with woody plants. Additional work is needed to evaluate other species of plants, to determine the best type of root cutting, and to determine the success of root promoting substances on stimulating root growth in highway planting sites. 


\author{
Nitrogen Availability to Woody Plant Species as \\ Influenced by Nitrogen Fixation
}

\title{
Abstract
}

Thirteen woody plant species were analyzed by acetylene reduction assay to determine their nitrogen fixation activity. Caragana arborescens Lam., Robinia fertilis Ashe, R. hispida L., R. pseudoacacia L., Alnus glutinosa (L.) Gaertn. Elaeagnus umbellata Thunb., E. angustifolia $\mathrm{L} .$, Shepherdia argentea Nutt., $\underline{\text { S. }}$ canadensis Nutt. Hippophae rhamnoides L., and Myrica pensylvannica Lois. were found to be active.

Nodules carried out nitrogen fixation best under low nitrogen fertility while at higher rates of fertilization or low temperatures the nodules ceased to funciion. Temperatures, which caused $\underline{A}$. glutinosa and $\underline{E}$. umbellata to defoliate, did not stop nodule activity at the time of defoliation.

Nodules on plants grown in a solution culture failed to excrete nitrogen into the growing medium. Therefore, it is believed increased nitrogen fertility around trees and shrubs which fix nitrogen is due to decomposing nodules and leaf litter.

Results

Both legume and non-legume trees and shrubs were found capable of fixing nitrogen and the amount fixed was substantial enough to support 
growth of that plant when no other nitrogen supply was added to it.

of the plants observed which might be a nitrogen fixing plant, Cercis canadensis was the only one which presented no evidence of nodule formation.

A $2.8^{\circ} \mathrm{C}$ temperature did not stop plant growth but did cause the nodule to become inactive with Robinia pseudoacacia. With the non-legumes Alnus glutinosa and Elaeagnus umbellata, nitrogen fixation occurred after the plants had defoliated in the fall when grown outdoors.

Nitrogen fertilization caused the nodules to cease to be active. When adequate nitrogen is present the nodule will not function but when deficiences occur nodules will form and their activity is capable of meeting the nitrogen needs of the plant.

\section{Application}

Nitrogen-fixing plants can be grown where due to location of the site or due to costs it is impossible to fertilize plants when they need nutrients. The plant material evaluated can support itself with a nitrogen supply and after a period of a few years will have the soil nitrogen supply built up so as to meet the requirements of other species. 
Response to Nitrogen from Three Slow Release Fertilizers

Abstract

The nitrogen fertilizers urea-formaldehyde, magnesium ammonium phosphate and isobutylidene diurea were evaluated for their slow release properties and contribution of nitrogen to the foliage of Cotoneaster divaricata Rehd. \& Wils. and Juniperus chinensis pfitzeriana Spaeth. Seasonal variations in the nitrogen content of the foliage were found. Statistical analysis indicated differences in nitrogen content of the foliage when different rates were applied, however, no differences in nitrogen content of the foliage occurred among the three fertilizers. Nitrogen deficiences did not occur on any treatment. Slow release fertilizers supplied nitrogen over extended periods with only one application.

\section{Results}

Cotoneaster divaricata still had the nitrogen content of its follage increased during the second season after application when treated with each slow release fertilizer. With Juniperus chinensis pfitzeriana no response occurred with any of the treatments.

Four tablets of the urea-formaldehyde, 56.7 grams of isobutylidene diurea, and $226.8 \mathrm{~g}$ of magnesium ammonium phosphate per 
plant each increased the nitrogen in $\underline{C}$. divaricata foliage significantly over the smaller rates applied.

\section{Applications}

The use of slow release nitrogen fertilizers may be of benefit as a nutrient source for highway landscape plants. Using such fertilizers at the time of planting could supply nitrogen over a significant period without making frequent applications. With slow release fertilizers a nitrogen supply would be present during the first few years when it is most critical to plant establishment.

However, the growth response between treatments in this experiment was so limited that additional research should be carried out on highway sites before recommending a change in specifications for planting on Indiana highways. 


\section{Factors Influencing Dehardening and Rehardening of Forsythia $\times$ intermedia Stems}

Abstract

Hardiness of stems of Forsythia $\mathrm{x}$ intermedia Zabel growing outdoors was determined from mid-November 1970 to early April 1971. At different times in winter, stem pieces from plants were subjected to different time-temperature combinations to study temperature required for dehardening and rehardening.

Once the cold requirement of dormancy had been fulfilled, the temperature and exposure required for significant dehardening decreased, reaching a mimimum in late winter. The daily duration of low temperature required to prevent dehardening increased after dormancy was broken, but was constant throughout the remainder of winter. Stems failed to reharden beyond the level of hardiness found following dehardening, but before any exposure to low temperature. Attempts to modify dehardening with growth regulators applied in the fall to non-hardy plants were unsuccessful.

\section{Discussion and Conclusions}

Dormancy was found to retard dehardening in Forsythia, but not to prevent it entirely. In December, before dormancy was completed, 6 days exposure to $21.2^{\circ} \mathrm{C}$ did not give significant dehardening, 
. 
In mid-January.

Once the cold requirement of dormancy had been fulfilled, the temperature and exposure required for significant dehardening decreased, reaching a minimum in late winter. Even though dehardening occurred more readily throughout the winter, it appears that 5 to 6 days of warm weather are required before dehardening reaches a maximum. The rate of dehardening may remain constant at temperatures greater than 21.2 C as, in these experiments, higher temperatures did not further stimulate dehardening. Additional studies are needed to determine the effects on dehardening of prolonged exposure to higher temperatures than were used here.

A relationship was also found between dormancy and the daily duration of low temperature required to prevent dehardening. In midDecember, 4 hours exposure to low temperature $\left(4.4^{\circ} \mathrm{C}\right)$ daily prevented dehardening for 6 days, while 6 hours daily were required in January and March. However, as both dormancy and low temperature retard dehardening, it is possible that the daily duration of low temperature required to prevent dehardening would be less during dormancy .

Although applications of GA to unhardened plants in the fall did not delay the period of maximum hardiness, they did increase dehardening in middle and late winter. It is possible that plants treated with GA in the fall will not become as cold resistant as untreated plants, but further studies are needed to determine this. Further studies are also needed to determine residual effects of GA and Alar applied before September 15 . 

Rehardenting

Extensive rehardening of Forsythia stems following dehardening appears unlikely. Stems dehardened in late January and then exposed again to low temperature did not reharden, but dehardened no further. In late winter, stems apparently required a short adjustment period (2 days) to low temperature before dehardening stopped. After the 2-day adfustment period, dehardening stopped and rehardening began, and at the end of the rehardening period, the stems had returned to the level of hardiness found before exposure to low temperature. It is possible that longer exposure than 6 days to $4.4^{\circ} \mathrm{C}$ would cause further rehardening. However, without photosynthesis, it is doubtful that rehardening beyond the level preceding any dehardening can be accomplished, since each period or warm temperature causes further depletion of reserve foods.

Practical Applications

These results indicate that plant material used in highway landscapes should be stored under controlled temperatures, at the nursery and also by the highway department prior to planting. Premature warming of storage facilities will increase respiration rates and rapidly deplete food reserves. This means that by the time plant materials reach the planting site they are in a weakened 

state and stand little chance of survival in the adverse conditions usually found at these sites. If plant materials recelve the proper low temperatures to prevent dehardening and depletion of stored foods, better survival and quicker establishment are likely under the stress of highway planting sites.

Low temperatures need not be provided constantly to maintain plant materfal in a hardened state or state of low metabolic activity. As shown in this research 6 hours of low temperature $\left(4^{\circ} \mathrm{C}\right)$ dally are adequate to maintain hardiness. Without a daily exposure to low temperature, plant materials lose hardiness in as little as 2 to 4 days of high temperature $\left(21^{\circ} \mathrm{C}\right)$. Although this study utilized Forsythia intermedia, implications are that plant materials may be transported only 15-16 hours without cold temperatures to prevent dehardening.

Rehardening studies show that once plant materials are dehardened they are unlikely to reharden. Of course without follage and the proper temperature no metabolites are manufactured. 


\section{Conclusions and Practical Applications}

\section{Weed Contro1 in Landscape P1antings}

A. Where possible, based on plant tolerance, dichlobenil (Casoron) should be incorporated in mulch before the mulch is placed around landscape plants. Weed control is nearly $100 \%$ effective for one year and often $90 \%$ for up to 3 years. Some perennial weeds are controlled.

B. Combinations of simazine at $1 \mathrm{lb} / \mathrm{A}$ plus diphenamid at $4 \mathrm{lb} / \mathrm{A}$ may be used safely on most landscape plantings. Almost all annual weeds are controlled for one season.

C. The use of paraquat around the bases of shade trees, guard rails, and signs will reduce the amount of weed growth. Simazine should be added to the paraquat to prevent return growth. Extreme caution should be used when applying paraquat. Follow all directions carefully.

\section{Practica1 App1ications}

a. Some herbicides are now being used in landscape plantings on Indiana highways.

b. Additional herbicide usage needs to be made and techniques taught to highway personnel.

\section{Plant Establishment}

A. The use of Teton and/or Travois alfalfa in the roadside seeding mixtures will help improve the rate of covering and provide greater erosion control. 
B. Brds foot trefoil, and various clover did not provide rapid enough cover.

C. Seeding of woody plants was not successful enough to warrant recommendation.

D. The use of root cuttings of Rhus sp. and Robinia sp. covered with a light mulch will provide a rapid shrub cover on steep slopes. Only spring planting has proven successful.

E. Nitrogen fixing ornamental plants should be used more in landscape plantings.

F. Slow release nitrogen fertilizers need additional evaluation before recommending their use in highway landscape plantings. 1. Practical Applications

a. The use of alfalfas in seeding mixtures is now being considered by the Indiana Highway Department.

b. A list of nitrogen fixing ornamentals is being prepared for use by landscape design personnel of Roadside Development Staff.

III. Cold-hardiness

A. Dehardening and a break in dormancy of some ornamentals can occur if winter storage temperatures are too warm for even

a few hours.

1. Practical Application

a. Plant sources should be checked to insure adequate storage facilities are available. 

